\title{
Exigência de lisina digestível para poedeiras semipesadas de 50 a 66 semanas de idade
}

\author{
[Digestible lysine requirement for laying hens from 50 to 66 weeks of age] \\ R.V. Nunes ${ }^{1}$, S.E. Schneider ${ }^{1}$, C. Souza ${ }^{1 *}$, C.P. Sangali ${ }^{2}$, C. Polese ${ }^{1}$, \\ R.S. Bueno ${ }^{3}$, F.M. Vieites ${ }^{1}$ \\ ${ }^{1}$ Universidade Estadual do Oeste do Paraná - Marechal Cândido Rondon, PR \\ ${ }^{2}$ Universidade Estadual de Maringá - Maringá, PR \\ ${ }^{3}$ Universidade de São Paulo - FZEA - Pirassununga, SP \\ RESUMO
}

\begin{abstract}
Com o objetivo de determinar a exigência de lisina digestível para poedeiras semipesadas no período de 50 a 66 semanas de idade, foi realizado experimento utilizando-se 150 poedeiras Shaver Brown, distribuídas em delineamento inteiramente ao acaso, com cinco tratamentos (níveis de lisina digestível: 0,$79 ; 0,82 ; 0,85 ; 0,88$ e 0,91\%), seis repetições e cinco aves por unidade experimental. Foram avaliados a produção de ovos, peso médio e a massa de ovos, consumo de ração e de lisina, conversão alimentar por massa e por dúzia de ovos, gravidade específica, unidade Haugh, o índice de gema e albúmen, porcentagem de albúmen, gema e casca. O consumo de ração, a conversão alimentar por massa e dúzia de ovos, a produção, o peso e a massa de ovos não foram influenciados $(\mathrm{P}>0,05)$ pelos níveis de lisina digestível. Houve aumento linear no consumo de lisina $(\mathrm{P}<0,01)$ com o incremento dos níveis desse aminoácido nas rações. As porcentagens de albúmen, gema e casca não foram influenciadas $(\mathrm{P}>0,05)$ pelos níveis de lisina digestível estudados. Os níveis de lisina influenciaram de forma quadrática $(\mathrm{P}>0,05)$ a unidade Haugh e o índice de albúmen, sendo estimados os níveis de 0,884 e $0,868 \%$ de lisina digestível, respectivamente. Para o índice de gema, a associação do modelo quadrático ao Linear Response Plateau (LRP) estimou o nível de 0,903\% de lisina digestível. Quando o objetivo é maximizar a qualidade interna dos ovos, recomenda-se o nível dietético de 0,884\%, 0,868\% e 0,903\% de lisina digestível para unidade Haugh, índice de albúmen e índice de gema, respectivamente.
\end{abstract}

Palavras-chave: aminoácido, Shaver Brown, produção de ovo, qualidade de ovo

\begin{abstract}
With the objective of determining the requirement of digestible lysine for brown-egg laying hens in the period from 50 to 66 weeks of age, an experiment was carried out using 150 Shaver Brown laying hens, distributed in a completely randomized design, with five treatments (digestible lysine levels: 0.79, 0.82, 0.85, 0.88 and $0.91 \%$ ), six replications and five birds per experimental unit. The production of eggs, weight and the egg mass, feed intake and lysine, feed mass and dozen eggs, specific gravity, Haugh unit, yolk and albumen index, percentage of albumen, yolk and bark were analyzed. Feed intake, feed conversion per dozen of eggs $s$ and per egg mass, egg production, egg weight and egg mass were not influenced $(P>0.05)$ by digestible lysine levels. There was a linear increase in lysine intake $(P<0.01)$ with increasing levels of this amino acid in the diets. The albumen, yolk and shell percentages were not influenced $(P>0.05)$ by studied digestible lysine levels. Lysine levels had a quadratic effect $(P>0.05)$ Haugh unit and albumen index being estimated as 0.884 and $0.868 \%$ digestible lysine levels, respectively. For yolk index, the association of the quadratic model to Linear Response Plateau (LRP) estimated the level of $0.903 \%$ digestible lysine. When the aim is to maximize the internal egg quality, a dietary level of $0.884 \%, 0.868 \%$ and $0.903 \%$ digestible lysine for Haugh unit, albumen index and yolk index, respectively is recommended.
\end{abstract}

Keywords: amino acid, Shaver Brown, egg production, egg quality

Recebido em 3 de julho de 2014

Aceito em 18 de junho de 2015

*Autor para correspondência (corresponding author)

E-mail: cleversonsz@hotmail.com 


\section{INTRODUÇÃO}

Nos últimos anos, a maioria das linhagens de aves de postura apresentaram consideráveis aumentos na produtividade, principalmente estimulados pelos avanços na genética e na nutrição. Contudo, ainda existem questões relacionadas principalmente com a nutrição que precisam de mais estudos.

A formulação de dietas para galinhas poedeiras evoluiu para o conceito de proteína ideal, contribuindo para a redução dos níveis proteicos da ração, garantindo formulações de menor custo, com redução da excreção de nitrogênio e mantendo adequado o desempenho das aves (Oliveira Neto e Oliveira, 2009), já que consiste no balanço exato de aminoácidos, capaz de fornecer, sem excesso ou falta, todos os aminoácidos necessários para o máximo desempenho das aves.

Entretanto, para a formulação de dietas com base nesse conceito, é imprescindível estimar a exigência nutricional de lisina, pois este tem sido o aminoácido referência no estabelecimento da exigência dos demais aminoácidos (Moura, 2004). Isso ocorre devido à simplicidade de determinação analítica desse aminoácido e ao uso exclusivo na síntese de proteínas, ao contrário de outros aminoácidos que possuem outros propósitos metabólicos (Sá et al., 2007). Uma vez determinado o requerimento de lisina, as exigências dos demais aminoácidos podem ser facilmente calculadas (Oliveira Neto e Oliveira, 2009) com base em relações ideais da lisina com os mesmos.

No Brasil, a principal referência para os níveis de aminoácidos ideais são as Tabelas Brasileiras de Exigências Nutricionais para Aves e Suínos, propostas por Rostagno et al. (2000; 2005), as quais indicam os níveis de 0,718 e $0,750 \%$ de lisina digestível para poedeiras semipesadas em fase de produção, respectivamente.

Estudos mais recentes têm demonstrado que a exigência de lisina para poedeiras estaria entre 760 e $790 \mathrm{mg}$ por dia ou $0,76-0,79 \%$ da dieta, com base num consumo de 100 gramas por ave por dia (Cupertino et al., 2009; Rocha et al., 2009 e Silva et al., 2010), evidenciando a necessidade de constantes atualizações nas recomendações de aminoácidos em rações para poedeiras, tendo em vista o progresso genético e a possibilidade de as aves responderem de forma diferente aos diversos ambientes e às mudanças nos sistemas de produção.

Dessa forma, o presente estudo teve como objetivo avaliar o efeito de níveis de lisina digestível para poedeiras semipesadas, no período de 50 a 66 semanas de idade, com base no desempenho e qualidade dos ovos das aves.

\section{MATERIAL E MÉTODOS}

O experimento foi realizado no Núcleo de Estações Experimentais da Universidade Tecnológica Federal do Paraná - UTFPR, Campus de Dois Vizinhos, PR, de maio a agosto de 2009, utilizando-se 150 poedeiras semipesadas da linhagem Shaver Brown com 50 semanas de idade e peso corporal médio de 1,794 gramas, distribuídas em um delineamento inteiramente casualizado, contendo cinco tratamentos, seis repetições e 5 aves por unidade experimental.

$\mathrm{Na}$ fase de cria e recria, as aves foram manejadas conforme descrito no respectivo manual da linhagem. Na fase de produção, as aves foram alojadas em gaiolas de postura $(50 \times 40 \times 50 \mathrm{~cm})$, em um galpão de postura em alvenaria $(20 \mathrm{x}$ $8,5 \mathrm{~m})$, fechado com tela nas laterais, coberto com telha de cerâmica em duas águas, tendo orientação leste-oeste, pé-direito de $2,80 \mathrm{~m}$ de altura, apresentando quatro conjuntos de duas fileiras de gaiolas sobrepostas, separadas por um corredor central de $1,5 \mathrm{~m}$, sendo utilizada apenas uma fileira central. Até a $50^{\mathrm{a}}$ semana de idade, todas as aves consumiram ração de acordo com as recomendações de Rostagno et al. (2005), e ao início do período experimental, realizou-se a distribuição das aves, de acordo com o peso corporal.

Para determinação da exigência nutricional de lisina digestível, foram formuladas cinco dietas (Tab. 1), à base de milho e farelo de soja, com níveis de lisina digestível $(0,79 ; 0,82 ; 0,85 ; 0,88$; $0,91 \%)$, calculadas de acordo com os valores de composição química dos alimentos e de exigência nutricional propostos por Rostagno et al., (2005). Os teores de metionina+cistina, treonina e triptofano foram calculados de acordo com a relação aminoácido/lisina para poedeiras leves e semipesadas. 
Tabela 1. Composição centesimal e nutricional das rações experimentais

\begin{tabular}{|c|c|c|c|c|c|}
\hline \multirow[b]{2}{*}{ Ingredientes $(\mathrm{g} / \mathrm{kg})$} & \multicolumn{5}{|c|}{ Níveis de Lisina digestível (\%) } \\
\hline & 0,79 & 0,82 & 0,85 & 0,88 & 0,91 \\
\hline Milho Grão & 63,95 & 64,11 & 64,28 & 64,43 & 64,59 \\
\hline Farelo de Soja (45\%) & 21,76 & 21,55 & 21,33 & 21,13 & 20,92 \\
\hline Óleo de Soja & 2,21 & 2,16 & 2,10 & 2,05 & 1,99 \\
\hline Fosfato bicálcico & 2,11 & 2,11 & 2,11 & 2,11 & 2,11 \\
\hline Calcário calcítico & 9,41 & 9,41 & 9,41 & 9,41 & 9,41 \\
\hline L-Lisina HCL (78\%) & 0,130 & 0,175 & 0,220 & 0,264 & 0,309 \\
\hline DL-Metionina (98\%) & 0,151 & 0,173 & 0,206 & 0,228 & 0,250 \\
\hline L-Treonina (98\%) & 0,058 & 0,081 & 0,104 & 0,128 & 0,151 \\
\hline L-Triptofano $(98 \%)$ & 0,000 & 0,011 & 0,023 & 0,036 & 0,048 \\
\hline Suplemento Mineral/Vitamínico ${ }^{1}$ & 0,200 & 0,200 & 0,200 & 0,200 & 0,200 \\
\hline Antioxidante $^{2}$ & 0,020 & 0,020 & 0,020 & 0,020 & 0,020 \\
\hline Total & 100 & 100 & 100 & 100 & 100 \\
\hline Energia $(\mathrm{kcal} / \mathrm{kg})$ e nutrientes $(\%)$ & \multicolumn{5}{|c|}{ Composição calculada } \\
\hline Energia Metabolizável & 2,85 & 2,85 & 2,85 & 2,85 & 2,85 \\
\hline Proteína Bruta & 15,36 & 15,36 & 15,36 & 15,36 & 15,36 \\
\hline Cálcio & 4,20 & 4,20 & 4,20 & 4,20 & 4,20 \\
\hline Fósforo & 0,48 & 0,48 & 0,48 & 0,48 & 0,48 \\
\hline Sódio & 0,16 & 0,16 & 0,16 & 0,16 & 0,16 \\
\hline Lisina digestível & 0,79 & 0,82 & 0,85 & 0,88 & 0,91 \\
\hline Met+ Cis digestível & 0,60 & 0,62 & 0,65 & 0,67 & 0,69 \\
\hline Treonina digestível & 0,57 & 0,59 & 0,61 & 0,63 & 0,65 \\
\hline Triptofano digestível & 0,16 & 0,17 & 0,18 & 0,19 & 0,20 \\
\hline Valina digestível & 0,64 & 0,63 & 0,63 & 0,63 & 0,62 \\
\hline Isoleucina digestível & 0,58 & 0,58 & 0,58 & 0,57 & 0,57 \\
\hline Histidina digestível & 0,39 & 0,39 & 0,39 & 0,39 & 0,39 \\
\hline Arginina digestível & 0,93 & 0,91 & 0,91 & 0,90 & 0,90 \\
\hline \multicolumn{6}{|c|}{$\begin{array}{l}\text { Tíveis de garantia por kg do produto: vit. A: } 3.997 .500 \text { U.I.; Vit D3: } 2.880 .000 \text { U.I.; vit. E: } 7.500 \text { U.I.; vit. K3: } \\
\text { 1.500mg; vit. B1: } 750 \mathrm{mg} \text {; vit B2: } 2.505 \mathrm{mg} \text {; Vit B6: } 1.500 \mathrm{mg} \text {; vit. B12: } 7.500 \mathrm{mcg} \text {; Ác. Nicotínico: } 12.500 \mathrm{mg} \text {; Ác. } \\
\text { Pantotênico: } 4.005 \mathrm{mg} \text {; Biotina: } 50 \mathrm{mg} \text {; ác. Fólico: } 500 \mathrm{mg} \text {; Ferro: } 25.000 \mathrm{mg} \text {; Cobre: } 5.000 \mathrm{mg} \text {; Zinco: } 30.000 \mathrm{mg} \text {; } \\
\text { Manganês: } 40.000 \mathrm{mg} \text {; Selênio: } 128 \mathrm{mg} \text {; Iodo: 500mg; Cobaldo: } 500 \mathrm{mg} \text {; Bacitracina de Zinco: } 25.000 \mathrm{mg} \text {; } \\
\text { Antioxidante: } 15 \mathrm{~g} \text {; Veículo q.s.p.: 1.000g. }{ }^{2} \text { Butil-hidroxi-tolueno - antioxidante. }\end{array}$} \\
\hline
\end{tabular}

As rações foram fornecidas em comedouros tipo calha, três vezes ao dia ( $7 \mathrm{~h}, 13 \mathrm{~h}$ e $17 \mathrm{~h})$, sendo a água fornecida em bebedouros tipo nipple (taça), garantindo consumo de alimento e água $a d$ libitum durante todo o período experimental, que teve duração de 16 semanas, subdividido em quatro períodos de 28 dias. O programa de luz adotado foi de 16 horas de luz diária (natural+artificial), controlado automaticamente por timer.

Os parâmetros avaliados a cada período de 28 dias foram: consumo de ração, consumo de lisina, conversão alimentar por dúzia de ovos, conversão alimentar por massa de ovos, taxa de postura, peso de ovos, massa de ovos, porcentagem dos componentes dos ovos (casca, albúmen e gema), peso da casca por unidade de superfície de área (PSCA), espessura de casca, gravidade específica e qualidade interna dos ovos (unidades Haugh, índice de albúmen e de gema).

A produção média de ovos foi obtida registrando-se diariamente o número de ovos produzidos, incluindo os ovos quebrados, trincados e mal formados, sendo então calculada a taxa de postura, resultado da divisão do número de ovos coletados pelo número de aves por unidade experimental e pelo número de dias, expressos em porcentagem de ovos/ave/dia.

O consumo de ração foi avaliado semanalmente por meio da divisão da quantidade de ração consumida pelo número de aves em cada tratamento, expresso em gramas de ração por ave/dia. Conhecendo o consumo e a porcentagem de lisina na ração, determinou-se o consumo de lisina. 
A conversão alimentar por dúzias de ovos foi obtida por meio da divisão consumo total de ração, em $\mathrm{kg}$, pelo número de dúzia de ovos. A conversão por massa de ovos foi calculada dividindo-se o consumo médio de ração, em kg, pela massa de ovos produzida, em $\mathrm{kg}$.

Para a obtenção do peso médio dos ovos, foram utilizados todos os ovos íntegros, coletados nos quatro últimos dias $\left(25^{\circ}, 26^{\circ}, 27^{\circ}\right.$ e $28^{\circ}$ dia $)$ de cada período experimental, que foram pesados individualmente em balança com precisão de $0,001 \mathrm{~g}$. A média do peso dos ovos em cada unidade experimental foi obtida pela razão entre o peso total dos ovos durante os quatro dias de pesagem e o número de ovos coletados. A massa de ovos foi expressa em gramas de ovos por ave por dia, multiplicando-se o peso médio dos ovos coletados durante os quatro dias pela produção de ovos.

Para avaliação da qualidade interna e externa dos ovos, foi realizada uma amostragem de dois ovos por unidade experimental, coletados durante os quatro últimos dias de cada período. Os ovos foram submetidos à avaliação da gravidade específica, pelo método de flutuação, utilizando soluções de $\mathrm{NaCl}$ com concentrações de 1,075; 1,$080 ; 1,085 ; 1,090$ e 1,095 , aferidas por meio de um densímetro de petróleo, antes de cada teste. Os ovos foram submersos em recipientes graduados de 5 litros da menor para a maior concentração, quando flutuavam em uma determinada solução, os ovos eram retirados e o valor anotado. Após a determinação da gravidade específica, os ovos foram lavados em água destilada, secos com papel absorvente e quebrados para obtenção da porcentagem de seus componentes.

Após a ruptura da casca, realizou-se a separação e pesagem da gema. As cascas permaneceram por 48 horas em temperatura ambiente e depois foram colocadas em estufa com circulação de ar a $65^{\circ} \mathrm{C}$ por 8 horas para secagem completa e posterior pesagem. O peso do albúmen foi obtido subtraindo-se do peso do ovo íntegro o peso da casca e da gema. Com a obtenção desses resultados foram calculadas as porcentagens de casca, albúmen e gema.

A espessura da casca foi determinada em dois pontos distintos do meridiano da mesma, utilizando-se para isso um micrômetro com precisão de $0,001 \mathrm{~mm}$. As cascas foram pesadas juntamente com suas membranas em balança analítica após a secagem em temperatura ambiente e em estufa.

Para determinação da unidade Haugh, foi utilizada a metodologia descrita por Haugh (1937). Essa unidade correlaciona o peso do ovo (g) com a altura do albúmen (mm) espesso. De modo geral, quanto maior o valor da unidade Haugh, melhor a qualidade do ovo (Ramos et al., 2010).

Os índices de albúmen (IA) e de gema (IG) foram calculados a partir dos diâmetros de albúmen e gema como seguem:

IA = altura do albúmen $(\mathrm{mm}) /$ diâmetro do albúmen (mm).

$\mathrm{IG}=$ altura da gema $(\mathrm{mm}) /$ diâmetro da gema (mm).

O peso da casca por unidade de superfície de área (PSCA) foi calculado utilizando-se a equação adaptada por Rodrigues et al. (1996): PSCA $=\left[\mathrm{PC} /\left(3,9782 \times \mathrm{PO}^{0,7056}\right)\right] \times 100$, em que:

PSCA = Peso da casa por unidade de superfície de área;

$\mathrm{PC}=$ Peso da casca $(\mathrm{g})$;

$\mathrm{PO}=$ Peso do ovo $(\mathrm{g})$.

Os dados foram submetidos às análises de variância e os tratamentos desdobrados em regressão polinomial. As estimativas dos níveis ótimos de lisina foram feitas pelos modelos Linear Response Plateau (LRP) e/ou quadrático e, quando possível o ajuste simultâneo de ambos os modelos, esse procedimento foi adotado, conforme descrito por Sakomura e Rostagno (2007).

Por esse método, as exigências são determinadas como sendo o primeiro ponto em que a resposta quadrática intercepta o platô do LRP. Esse ponto pode ser definido matematicamente, igualandose a equação quadrática ao valor da variável analisada (Y) estabelecido pelo platô do LRP. Considerando-se a equação quadrática como: $\mathrm{Y}=$ $\mathrm{ax}^{2}+\mathrm{bx}+\mathrm{c}$, os pontos de intersecção (exigência) do platô com a curva são calculados pela equação: 


$$
x=\frac{-b \pm \sqrt{b^{2}-4 a(c-y)}}{2 a}
$$

Todas as análises foram realizadas por intermédio do programa estatístico SAEG (Sistema para Análises Estatísticas e Genéticas), desenvolvido na Universidade Federal de Viçosa - UFV (1999), adotando-se o nível de 5\% de significância.

\section{RESULTADOS E DISCUSSÃO}

Não foi observado efeito significativo $(\mathrm{P}>0,05)$ dos níveis de lisina digestível sobre o consumo de ração das aves (Tab. 2). O consumo de lisina digestível teve resultado esperado, aumentando linearmente $(\mathrm{P}<0,05)$ conforme a elevação dos níveis na ração.

Tabela 2. Desempenho de poedeiras semipesadas alimentadas com rações contendo níveis de lisina digestível no período de 50 a 66 semanas de idade

\begin{tabular}{|c|c|c|c|c|c|c|}
\hline \multirow{2}{*}{ Variáveis } & \multicolumn{5}{|c|}{ Nível de lisina (\%) } & \multirow{2}{*}{$\mathrm{CV}(\%)$} \\
\hline & 0,79 & 0,82 & 0,85 & 0,88 & 0,91 & \\
\hline Consumo de ração (g/ave/dia) & 118,65 & 117,83 & 117,35 & 118,76 & 118,35 & 1,32 \\
\hline Consumo de lisina (mg/ave/dia) ${ }^{1 ; 2}$ & 937,35 & 966,21 & 997,45 & 1045,12 & 1077,00 & 1,56 \\
\hline CA por dúzia de ovos (kg/dúzia) & 1,60 & 1,71 & 1,61 & 1,62 & 1,64 & 4,76 \\
\hline CA por massa de ovos $(\mathrm{kg} / \mathrm{kg})$ & 1,98 & 2,16 & 2,02 & 2,05 & 2,05 & 5,21 \\
\hline Taxa de postura (\%) & 90,77 & 84,68 & 88,72 & 89,34 & 88,36 & 3,62 \\
\hline Peso de ovos (g) & 66,07 & 65,29 & 65,89 & 65,27 & 65,85 & 1,37 \\
\hline Massa de ovos (g/ave/dia) & 59,97 & 54,92 & 58,47 & 58,19 & 58,23 & 4,49 \\
\hline
\end{tabular}

$\mathrm{CA}=$ conversão alimentar; $\mathrm{CV}=$ coeficiente de variação

${ }^{1}$ Efeito linear $(\mathrm{P}<0,05)$;

${ }^{2} \mathrm{Y}=897,2430+35,7393 \mathrm{X}\left(\mathrm{R}^{2}=0,87\right)$.

Pesquisas com níveis de lisina na ração de poedeiras mostram resultados semelhantes aos encontrados neste estudo, nos quais os níveis de lisina não influenciaram o consumo alimentar das aves (Jordão Filho et al., 2006a e b; Sá et al., 2007; Cupertino et al., 2009; Schmidt et al., 2009). Pacheco et al. (2010) observaram influência dos níveis dietéticos $(0,5 ; 0,6 ; 0,7 ; 0,8$ e $1,0 \%$ ) de lisina total sobre o consumo de ração de poedeiras semipesadas em duas fases avaliadas ( 24 a 36 semanas e 48 a 60 semanas) com menor consumo de ração para o menor nível avaliado $(0,5 \%$ de lisina total). Trindade Neto et al. (2011) observaram influência dos níveis de lisina dietéticos sobre o consumo de poedeiras ISA Brown em duas fases avaliadas (24 a 36 semanas e 48 a 60 semanas), estimando a exigência de lisina com base no consumo em 0,728 e $0,608 \%$ para os períodos, respectivamente. Possivelmente a resposta encontrada por esses autores pode estar relacionada ao desequilíbrio aminoacídico ocorrido nessas dietas, ativando os mecanismos responsáveis pela redução no consumo de alimentos (Andriguetto e Perly, 2003).

A conversão alimentar por dúzia e por massa de ovos e a taxa de postura das aves não foram influenciadas $(\mathrm{P}>0,05)$ pelos níveis de lisina digestível na ração. Esse resultado indica que a necessidade de lisina digestível pelas aves é igual ou menor do que o nível mais baixo utilizado no presente trabalho, que foi de $0,790 \%$ ou $937,35 \mathrm{mg}$ de lisina digestivel/ave/dia.

Nos últimos anos, vários estudos têm sido realizados para avaliar o efeito de diferentes níveis de lisina digestível na dieta sobre o desempenho e produção de ovos em aves de postura (Sá et al., 2007; Lima e Silva, 2007; Cupertino et al., 2009; Rocha et al., 2009; Jardim Filho et al., 2011; Trindade Neto et al., 2011) e em todos esses estudos as exigências de lisina digestível das aves para máxima produção de ovos e mínima conversão alimentar ficaram abaixo de 0,79\%. Em contrapartida, Panda et al. (2012) concluíram que um nível de $0,8 \%$ de lisina para Dahlem Red hens já é o suficiente para alcançar um ótimo desempenho. Sá et al. (2007) avaliaram o efeito de níveis crescentes de lisina digestível $(0,584 ; 0,634 ; 0,684 ; 0,734$ e $0,784 \%$ ) na ração de poedeiras semipesadas, no período de 34 a 50 semanas de idade, determinando os níveis de $0,69 \%$ e $0,71 \%$ para mínima conversão alimentar e máxima produção de ovos das aves, respectivamente. Resultado 
semelhante foi verificado por Lima e Silva (2007), que, trabalhando com poedeiras semipesadas de 40 a 56 semanas, constataram que os melhores valores de produção de ovos foram observados com o menor nível de lisina utilizado $(0,71 \%)$. Em estudos mais recentes, Cupertino et al. (2009) também encontraram valores próximos de $0,70 \%$ de lisina digestível para mínima conversão alimentar e máxima produção de ovos de poedeiras semipesadas, no período de 54 a 70 semanas de idade.

$\mathrm{O}$ peso dos ovos não foi influenciado $(\mathrm{P}>0,05)$ pelos níveis de lisina digestível na ração. Silva et al. (2010), trabalhando com dois níveis de lisina (0,85 e 1,0\%), e Jardim Filho et al. (2011), avaliando quatro níveis de lisina digestível $(0,6$; $0,7 ; 0,8 ;$ e $0,9 \%)$, também não encontraram efeito sobre o peso dos ovos. No entanto, em estudo anterior, Cupertino et al. (2009) observaram aumento linear no peso dos ovos conforme a elevação dos níveis de lisina digestível $(0,555,0,605,0,655,0,706$ e $0,755 \%)$ para poedeiras na fase de 54 a 70 semanas de idade. Esses resultados podem estar relacionados aos níveis mais baixos de lisina digestível utilizados pelos autores, indicando que a exigência de lisina para a variável peso dos ovos está abaixo de $0,79 \%$.

A massa de ovos também não foi influenciada pelos níveis de lisina da ração, sendo encontrado valor médio de 57,96g/ave/dia, o que corrobora o observado por Jordão Filho et al. (2006b), que encontraram 58,06g/ave/dia ao trabalharem com níveis de lisina total variando de 0,79 a $1,03 \%$ da ração. Nesse contexto, a ração contendo $0,79 \%$ de lisina digestível atendeu às exigências nutricionais das poedeiras semipesadas Shaver Brown para a variável massa de ovos, e ainda superou os valores indicados no manual da linhagem (47,8g/ave/dia).

A qualidade da casca dos ovos, determinada pelas variáveis gravidade específica, espessura e PSCA, não foi afetada pelos níveis de lisina digestível da ração (Tab. 3).

Tabela 3. Parâmetros de qualidade do ovo de poedeiras semipesadas alimentadas com rações contendo níveis de lisina digestível no período de 50 a 66 semanas de idade

\begin{tabular}{|c|c|c|c|c|c|c|}
\hline \multirow{2}{*}{ Variáveis } & \multicolumn{5}{|c|}{ Nível de lisina (\%) } & \multirow{2}{*}{$\mathrm{CV}(\%)$} \\
\hline & 0,79 & 0,82 & 0,85 & 0,88 & 0,91 & \\
\hline Gravidade específica & 1,089 & 1,091 & 1,090 & 1,089 & 1,090 & 0,110 \\
\hline Espessura de casca (mm) & 0,440 & 0,453 & 0,454 & 0,452 & 0,456 & 2,545 \\
\hline $\operatorname{PSCA}\left(\mathrm{mg} / \mathrm{cm}^{2}\right)$ & 8,439 & 8,493 & 8,479 & 8,450 & 8,466 & 1,810 \\
\hline Casca $(\%)$ & 9,780 & 9,853 & 9,833 & 9,797 & 9,768 & 3,124 \\
\hline Albúmen (\%) & 63,132 & 63,763 & 63,274 & 64,503 & 64,288 & 1,893 \\
\hline $\operatorname{Gema}(\%)$ & 27,196 & 26,385 & 27,072 & 25,697 & 26,022 & 3,981 \\
\hline Unidade Haugh ${ }^{1}$ & 71,996 & 77,228 & 78,092 & 81,656 & 81,690 & 6,086 \\
\hline Índice de albúmen ${ }^{1}$ & 0,061 & 0,081 & 0,076 & 0,081 & 0,078 & 13,938 \\
\hline Índice de gema $^{1 ; 2}$ & 0,400 & 0,407 & 0,422 & 0,428 & 0,435 & 2,350 \\
\hline
\end{tabular}

Tais resultados corroboram Novak et al. (2004), Jordão Filho et al. (2006a,b) e Lima e Silva (2007) e demonstram que os níveis de lisina não influenciam a qualidade externa da casca dos ovos.

Fatores como períodos prolongados de estocagem aliados a elevadas temperaturas e baixa umidade relativa do ar podem alterar a gravidade específica e a porcentagem de casca (Barbosa et al., 2008; Jordão Filho et al., 2006a; Garcia et al., 2010).
Os níveis de lisina não influenciaram $(\mathrm{P}>0,05)$ as porcentagens de casca, albúmen e gema, mas tiveram efeito quadrático $(\mathrm{P}<0,05)$ sobre a unidade Haugh, o índice de albúmen e índice de gema. A exigência estimada pelo modelo quadrático para melhor unidade Haugh e índice de albúmen foi de $0,884 \%$ e $0,868 \%$ (Fig. 1), que corresponde a consumo de 1.049,84 e $1.030,84 \mathrm{mg} / \mathrm{ave} / \mathrm{dia}$ de lisina digestível, respectivamente. 

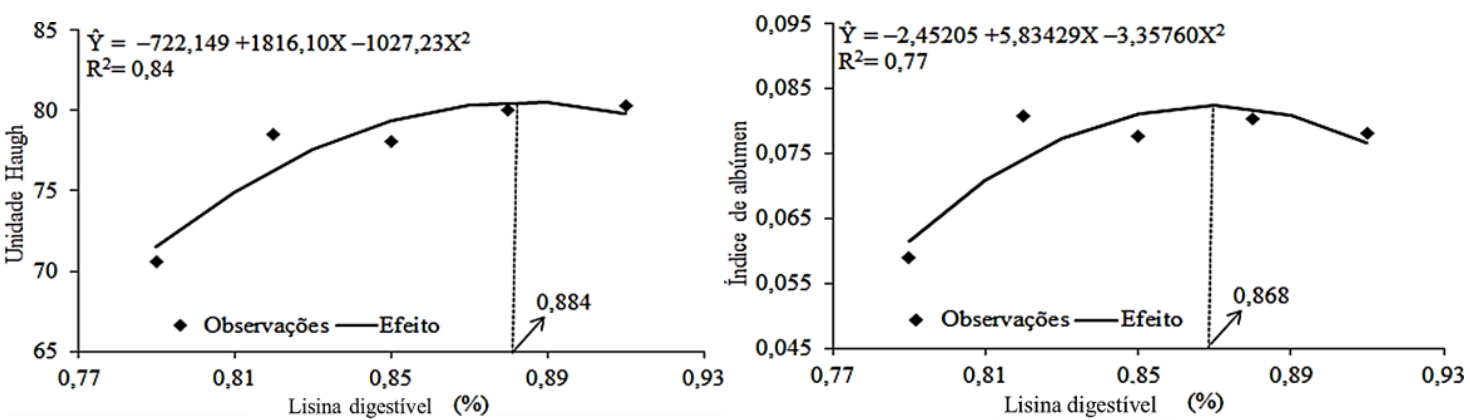

Figura 1. Unidade Haugh e índice de albúmen de ovos de poedeiras semipesadas Shaver Brown de 50 a 66 semanas de idade, em função do nível de lisina digestível na ração.

Para o índice de gema, a exigência estimada com a derivação da equação quadrática foi de $0,947 \%$ (Fig. 2). Como pode ser observado, esse valor está acima do nível máximo de lisina digestível avaliado no presente estudo, o que se explica, segundo Sakomura e Rostagno (2007), devido ao fato de o modelo quadrático, em alguns casos, superestimar o nível ótimo do elemento testado.
De acordo com esses autores, o procedimento estatístico mais indicado para a determinação do nível ótimo de lisina digestível seria por meio da associação do modelo quadrático ao LRP. Nesse procedimento, o nível ótimo de lisina digestível é dado pelo primeiro intercepto da equação quadrática com o platô do LRP.

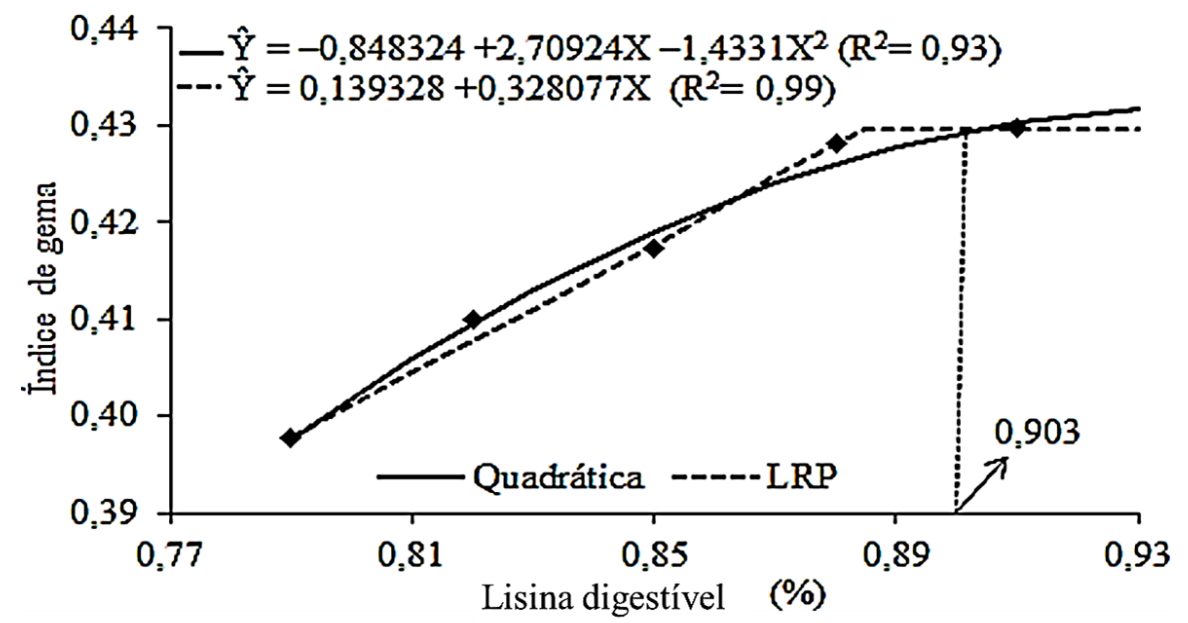

Figura 2. Índice de gema dos ovos de poedeiras semipesadas Shaver Brown de 50 a 66 semanas de idade, em função dos níveis de lisina digestível das rações.

Utilizando o procedimento descrito anteriormente, a exigência estimada para melhor índice de gema foi de $0,903 \%$, que corresponde a consumo de $1.068,70 \mathrm{mg} / \mathrm{ave} / \mathrm{dia}$ de lisina digestível. Para a unidade Haugh e o índice de albúmen, não foi possível determinar o nível de lisina por esse modelo em razão da falta de ajuste do LRP aos dados.

Os resultados encontrados na literatura supracitada para variáveis de qualidade de ovos são bastante controversos, o que pode ser explicado em virtude de essas variáveis serem influenciadas por fatores diversos, como tempo de armazenamento dos ovos e a idade das aves (Silversides e Scott, 2001), a temperatura no ambiente de produção (Faria et al., 2001) e a variação nos aparelhos usados para determinar as medidas de altura e diâmetros, de albúmen e gema, podem contribuir para as variações entre os resultados experimentais. 
Prochaska et al. (1996) avaliaram a influência da ingestão de rações com três níveis de lisina (677; 1.154 e $1.613 \mathrm{mg} /$ ave/dia) sobre os componentes dos ovos (sólidos do albúmen, sólidos de gema, proteína do albúmen e proteína da gema) de poedeiras de 42 a 64 semanas de idade e detectaram efeito significativo nas variáveis avaliadas, de modo que o maior nível de ingestão de lisina promoveu a maior resposta desses componentes. Novak et al. (2004) também observaram aumento significativo no percentual de albúmen dos ovos de poedeiras alimentadas com 959mg de lisina total/ave/dia em comparação aos ovos das aves alimentas com $860 \mathrm{mg}$ de lisina total/ave/dia, e esse aumento se refletiu diretamente no percentual de sólidos do albúmen.

Em pesquisa com poedeiras semipesadas e avaliando a unidade Haugh e os índices de gema e de albúmen, Sá et al. (2007) não observaram efeito dos níveis de lisina $(0,584 ; 0,634 ; 0,684$; 0,734 e $0,784 \%$ ) sobre esses parâmetros de qualidade do ovo. Trabalhando com aves no período de 54 a 70 semanas de idade, Cupertino et al. (2009) também não observaram efeito dos níveis de lisina sobre a qualidade interna dos ovos de poedeiras semipesadas.

Resultados discrepantes foram obtidos por Goulart (1997), que observou redução linear nas unidades Haugh para ambas as linhagens (leves e semipesadas). Naquele estudo, o autor também observou efeitos significativos (quadrático para aves leves e linear para semipesadas) dos níveis de lisina da dieta $(0,54$ a $0,840 \%)$ sobre o índice de albúmen dos ovos.

\section{CONCLUSÕES}

A exigência de lisina digestível para poedeiras semipesadas no período de 50 a 66 semanas de idade é igual ou inferior a $0,790 \%$, levando em consideração o desempenho e a qualidade externa dos ovos. Quando o objetivo é maximizar a qualidade interna dos ovos, recomenda-se o nível dietético de $0,884 \%$, $0,868 \%$ e $0,903 \%$ de lisina digestível para unidade Haugh, índice de albúmen e índice de gema, respectivamente.

\section{REFERÊNCIAS}

ANDRIGUETTO, J. M.; PERLY, L. Nutrição animal. São Paulo: Nobel, 2003. 390p.

BARBOSA, N.A.A.; SAKOMURA, N.K.; MENDONÇA, M.O. et al. Qualidade de ovos comerciais provenientes de poedeiras comerciais armazenados sob diferentes tempos e condições de ambientes. Ars Vet., v.24, p.127-133, 2008.

CUPERTINO E.S.; GOMES, P.C.; ALBINO, L.F.T. et al. Exigência nutricional de lisina para galinhas poedeiras de 54 a 70 semanas de idade. Rev. Bras. Zootec., v.38, p.480-487, 2009.

FARIA, D.E.; JUNQUEIRA, O.M.; SOUZA, P.A.; TITTO, E.A.L. Desempenho, temperatura corporal e qualidade de ovos de poedeiras alimentadas com vitaminas $\mathrm{D}$ e $\mathrm{C}$ em três temperaturas ambientes. Rev. Bras. Cienc. Avíc., v.3, p.49-56, 2001.

GARCIA, E.R.M.; ORLANDI, C.C.B.; OLIVEIRA, C.A.L. et al. Qualidade de ovos de poedeiras semipesadas armazenados em diferentes temperaturas e períodos de estocagem. Rev. Bras. Saúde Prod. Anim., v.11, p. 505-518, 2010.

GOULART, C.C. Exigência nutricional de lisina para poedeiras leves e semipesadas. 1997. 51f. Dissertação (Mestrado em Zootecnia) Universidade Federal de Viçosa, Viçosa, MG.

HAUGH, R.R. The Haugh unit for measuring egg quality. Uni. Stat. Egg Poult. Magazi., v.43, p.552-555, 1937.

JARDIM FILHO, R.M.; STRINGHINI, J.H.; CAFÉ, M.B. et al. Níveis de lisina digestível para poedeiras Lohmann LSL na fase de 16 a 25 semanas de idade. Rev. Bras. Zootec., v.40, p.1947-1954, 2011.

JORDÃO FILHO, J.J.; SILVA, J.H.V.; SILVA, E.L. et al. Efeitos da relação metionina + cistina:lisina sobre os desempenhos produtivo e econômico e a qualidade interna e externa dos ovos antes e após 28 dias de armazenamento. Rev. Bras. Zootec., v.35, p.1735-1743, 2006a

JORDÃO FILHO, J.J.; SILVA, J.H.V.; SILVA, E.L. et al. Exigência de lisina para poedeiras semipesadas durante o pico de postura. Rev. Bras. Zootec., v.35, p.1728-1734, 2006 b. 
LIMA, M.R.; SILVA, J.H.V. Efeito da relação lisina:arginina digestível sobre o desempenho de poedeiras comercias no período de postura. Acta Vet. Brasilica, v.1, p.118-124, 2007.

MOURA, A.M.A. Conceito da proteína ideal aplicada na nutrição de aves e suínos. Rev. Eletr. Nutr., v.1, p.31-34, 2004.

NOVAK, C.L.; YAKOUT, H.S.; SCHEIDELER, $S$. The combined effects of dietary lysine and total sulfur amino acid level on egg production parameters and egg components in dekalb delta laying hens. Poult. Sci., v.83, p.977-984, 2004.

OLIVEIRA NETO, A.R.O; OLIVEIRA, W.P. Aminoácidos para frangos de corte. In: REUNIÃO ANUAL DA SOCIEDADE BRASILEIRA DE ZOOTECNIA, 46., 2009, Maringá, PR. Rev. Bras. Zootec., v.38, p.205208, 2009.

PACHECO, B.H.C.; NETO, M.A.T.; ALBUQUERQUE, M.; CHAMMASS, E.A. Níveis de lisina digestível e zinco quelato sobre os parâmetros produtivos de poedeiras marrons. Rev. Bras. Zootec., v.39, p.2447-2452, 2010.

PANDA, A.K.; RAMA RAO, S.V.; RAJU, M.V.L.N. et al. Effect of nutrient density on production performance, egg quality and humoral immune response of brown laying (Dahlem Red) hens in the tropics. Trop. Anim. Health Prod., v.44, p.293-299, 2012.

PROCHASKA, J.F.; CAREY, J.B.; SHAFER, D.J. The effect of L-lysine intake on egg component yield and composition in laying hens. Poult. Sci., v.75, p.1268-1077, 1996.

RAMOS, K.C.B.T.; CAMARGO A.M.; OLIVEIRA, É.C.D. et al. Avaliação da idade da poedeira, da temperatura de armazenamento e do tipo embalagem sobre a qualidade de ovos comerciais. Rev. Cienc. Vida., v.30, p.37-46, 2010.

ROCHA, T.C.; GOMES, P.C.; DONZELE, J.L. et al. Níveis de lisina digestível em rações para poedeiras no período de 24 a 40 semanas de idade. Rev. Bras. Zootec., v.38, p.1726-1731, 2009.
RODRIGUES, P.B.; BERTECHINI, A.G.; OLIVEIRA, B.C. et al. Fatores nutricionais que influenciam a qualidade do ovo no segundo ciclo de produção. I. Níveis de aminoácidos sulfurosos totais. Rev. Bras. Zootec., v.25, p.248-260, 1996.

ROSTAGNO, H.S.; ALBINO, L.F.T.; DONZELE, J.L. et al. Tabelas brasileiras para suínos e aves: composição de alimentos e exigências nutricionais. Viçosa, MG: Universidade Federal de Viçosa, 2000. 141p.

ROSTAGNO, H.S.; ALBINO, L.F.T.; DONZELE, J.L. et al. Tabelas brasileiras para suínos e aves: composição de alimentos e exigências nutricionais. 2.ed. Viçosa, MG: Universidade Federal de Viçosa, 2005. 186p.

SÁ, L.M.; GOMES, P.C.; ROSTAGNO, H.S. et al. Exigência nutricional de lisina digestível para galinhas poedeiras no período de 34 a 50 semanas de idade. Rev. Bras. Zootec., v.36, p.1829-1836, 2007.

SAKOMURA, N.K.; ROSTAGNO, H.S. Métodos de pesquisa em nutrição de monogástricos. Jaboticabal, SP: FUNEP, 2007. $283 p$.

SCHMIDT, M.; GOMES, P.C.; ROSTAGNO, H.S. et al. Exigência nutricional de lisina digestível para poedeiras semipesadas no segundo ciclo de produção. Rev. Bras. Zootec., v.38, p.1956-1961, 2009.

SILVA, M.F.R; FARIA, D.E; RIZZOLI, P.W. et al. Desempenho, qualidade dos ovos e balanço de nitrogênio de poedeiras comerciais alimentadas com ração contendo diferentes níveis de proteína bruta e lisina. Rev. Bras. Zootec., v.39, p.1280-1285, 2010.

SILVERSIDES, F.G.; SCOTT, T.A. Effect of storage and layer age on quality of eggs from two lines of hens. Poult. Sci., v.80, p.1240-1245, 2001.

TRINDADE NETO, M.A.; PACHECO, B.H.C.; ALBUQUERQUE, R. et al. Dietary effects of chelated zinc supplementation and lysine levels in ISA Brown laying hens on early and late performance, and egg quality. Poult. Sci. v.90, p.2837-2844, 2011

SISTEMA para análises estatísticas e genéticas SAEG. Viçosa, MG: UFV, 1999. 59p. (Manual do usuário). 